\title{
Scientometric Analysis of Medical Research in Bangladesh
}

\author{
SK Biswas ${ }^{1}$, M Akhtaruzzaman ${ }^{2}$ \\ ${ }^{1}$ Dept of Biochemistry, Bangabandhu Sheikh Mujib Medical University (BSMMU), Dhaka \\ ${ }^{2}$ Dept of Biochemistry, Shaheed Suhrawardy Medical College, Dhaka
}

Scientometrics is the science of measuring and analyzing research or scientific performance. It is a common trend to use different scientometric indices (number of publications, number of citations, impact factor, h-index etc.) to evaluate research performance of a research group, a department, an institute, a country etc. Evaluation of research perormance is very important to know the real status of research activities of a country or an institute campared with that of others. Scientometric analysis is also extremely essential to plan appropriate measures to be taken to upgrade the research activities.

Biomedical research enriches our understanding of pathophysiological processes of different diseases as well as contributes to the preventive and curative measures. The quality of medical research in Bangladesh is generally considered as very poor. However, whether the real situation is worse or better than the conventional view is not very clear because of lack of scientometric analyses of research activities conducted in Bangladesh. Therefore it is difficult to identify the strengths and weaknesses of medical research in Bangladesh and to make any plan to upgrade medical research activities conducted in Bangladesh.

Scientometric evaluation of research performance is a very laborious task in spite of the availability of publication and citation database in the internet. Some institutes have numerous variations in their name and many publications share multiple collaborations among different institutes. These facts complicate to identify the number of publications or citations obtained by a particular institute over a period of time. In addition, direct comparison of number of

Bangladesh J Med Biochem 2012; 5(1): 3-4 publications and citations among institutes/countries is not very meaningful unless the associated factors relavent to research performance are carefully considered. A few of these factors include socioeconomic and political stability, national and institutional commitment, size of the institute, number of faculty members and investigators involved in research, number of graduate and post-graduate courses conducted, availability of research infrastructure and funding. A recent analysis compared research performance of Bangladesh with India, Pakistan and Sri Lanka considering research publications from all subject areas ${ }^{1}$. It showed that the total number of citable publications of India is more than 15, 40 and 90 times higher than those of Pakistan, Bangladesh and Sri Lanka, respectively, during a period from 1996 to 2007. However, additional analysis showed that number of citations per publication is the highest for Sri Lanka (6.17) followed by Bangladesh (4.64), India (4.59), and Pakistan (3.38) over the same period of time 1 .

A quick search in the SCImago Journal \& Country Rank (SJR) website ${ }^{2}$, that uses publication and citation database of Scopus, can provide comparative data of scientometric analysis of medical research performance of Bangladesh with other countries. Using the data obtained from SJR website for the period 199620102, Table 1 compares medical research performance (subject area 'Medicine' including all categories) of Bangladesh with that of India, Pakistan and the United States of America (USA), a superpower in scientific performance. It clearly shows that numbers of publications and citations of India and the USA are very high compared with those of Bangladesh and 
Pakistan. However, Bangladesh received more citations per publication compared with India and Pakistan, and percentage of cited documents of Bangladesh was found higher than Pakistan and very similar to India; although the USA obtained extremely high values for both of these indices. Table 1 also shows that there is an involvement of more than one country in about $50 \%$ of all the publications of Bangladesh, which is at best $20 \%$ for the other countries analyzed here.

Table-I: Some indicators of medical research performance of selected countries (1996-2010)

\begin{tabular}{llllll}
\hline Country & $\begin{array}{l}\text { Citable } \\
\text { Publications }\end{array}$ & Citations & $\begin{array}{c}\text { Citations/ } \\
\text { publication }\end{array}$ & $\begin{array}{l}\text { \% cited } \\
\text { documents }\end{array}$ & $\begin{array}{c}\text { \% publications with } \\
>1 \text { country }\end{array}$ \\
\hline Bangladesh & 2,676 & 23,411 & 8.75 & 64.9 & 46.57 \\
India & 78,588 & $4,51,499$ & 5.87 & 65.6 & 12.81 \\
Pakistan & 9,905 & 43,125 & 4.35 & 59.3 & 19.26 \\
USA & & $2,99,37,005$ & 22.75 & 83.0 & 20.19 \\
\hline
\end{tabular}

SK Biswas, M Akhtaruzzaman

A detail scientometric analysis of medical research performance of Bangladesh and its comparison with other countries is very important to obtain a clear picture and to take necessary measures to upgrade our research performance. At the same time it is also very important to evaluate the research performance of major medical research institutes of the country and to compare their performance among themselves and similar institues of other countries.

\section{References}

1. Mahbuba D, Rousseau R. Scientific research in the Indian subcontinent: selected trends and indicators 1973-2007 comparing Bangladesh, Pakistan and Sri Lanka with India, the local giant. Scientometrics 2010; 84: 403-420.

2. SCImago. (2007). SJR - SCImago Journal \& Country Rank. Retrieved August 21, 2012, from http://www.scimagojr.com 